(1)

CrossMark

\title{
Haemodynamic definitions and updated clinical classification of pulmonary hypertension
}

\author{
Gérald Simonneau ${ }^{1,2}$, David Montani (1) ${ }^{1,2}$, David S. Celermajer ${ }^{3}$, \\ Christopher P. Denton ${ }^{4}$, Michael A. Gatzoulis ${ }^{5}$, Michael Krowka ${ }^{6}$, \\ Paul G. Williams ${ }^{7}$ and Rogerio Souza $\mathbb{1}^{8}$ \\ Number 4 in the series \\ "Proceedings of the 6th World Symposium on Pulmonary Hypertension" \\ Edited by N. Galiè, V.V. McLaughlin, L.J. Rubin and G. Simonneau
}

Affiliations: ${ }^{1}$ Université Paris-Sud, AP-HP, Centre de Référence de l'Hypertension Pulmonaire, Service de Pneumologie, Département Hospitalo-Universitaire (DHU) Thorax Innovation (TORINO), Hôpital de Bicêtre, Le Kremlin-Bicêtre, France. ${ }^{2}$ INSERM UMR_S999, LabEx LERMIT, Hôpital Marie Lannelongue, Le PlessisRobinson, France. ${ }^{3}$ Faculty of Medicine and Health, The University of Sydney, Sydney, Australia. ${ }^{4}$ Centre for Rheumatology, Royal Free Campus, University College London, London, UK. ${ }^{5}$ Adult Congenital Heart Centre and National Centre for Pulmonary Hypertension, Royal Brompton and Harefield NHS Trust, and the National Heart and Lung Institute, Imperial College London, London, UK. ${ }^{6}$ Transplant Center, Mayo Clinic, Rochester, MN, USA. ${ }^{7}$ Center of Chest Disease and Critical Care, Milpark Hospital, Johannesburg, South Africa. ${ }^{8}$ Pulmonary Circulation Unit, Pulmonary Division, Heart Institute (InCor), Hospital das Clinicas da Faculdade de Medicina da Universidade de Sao Paulo, Sao Paulo, Brazil.

Correspondence: Gérald Simonneau, Service de Pneumologie, Centre de Référence de l'Hypertension Pulmonaire, CHU de Bicêtre, 78 rue du Général Leclerc, 94275 Le Kremlin-Bicêtre Cedex, France.

E-mail: gerald.simonneaudaphp.fr

@ERSpublications

State of the art and research perspectives of haemodynamic definitions and clinical classification of pulmonary hypertension http://ow.ly/TJeR30mgWKj

Cite this article as: Simonneau G, Montani D, Celermajer DS, et al. Haemodynamic definitions and updated clinical classification of pulmonary hypertension. Eur Respir J 2019; 53: 1801913 [https://doi.org/ 10.1183/13993003.01913-2018].

ABSTRACT Since the 1st World Symposium on Pulmonary Hypertension (WSPH) in 1973, pulmonary hypertension $(\mathrm{PH})$ has been arbitrarily defined as mean pulmonary arterial pressure (mPAP) $\geqslant 25 \mathrm{mmHg}$ at rest, measured by right heart catheterisation. Recent data from normal subjects has shown that normal mPAP was $14.0 \pm 3.3 \mathrm{mmHg}$. Two standard deviations above this mean value would suggest $\mathrm{mPAP}>20 \mathrm{mmHg}$ as above the upper limit of normal (above the 97.5th percentile). This definition is no longer arbitrary, but based on a scientific approach. However, this abnormal elevation of mPAP is not sufficient to define pulmonary vascular disease as it can be due to an increase in cardiac output or pulmonary arterial wedge pressure. Thus, this 6th WSPH Task Force proposes to include pulmonary vascular resistance $\geqslant 3$ Wood Units in the definition of all forms of pre-capillary $\mathrm{PH}$ associated with $\mathrm{mPAP}>20 \mathrm{mmHg}$. Prospective trials are required to determine whether this $\mathrm{PH}$ population might benefit from specific management.

Regarding clinical classification, the main Task Force changes were the inclusion in group 1 of a subgroup "pulmonary arterial hypertension (PAH) long-term responders to calcium channel blockers", due to the specific prognostic and management of these patients, and a subgroup "PAH with overt features of venous/ capillaries (pulmonary veno-occlusive disease/pulmonary capillary haemangiomatosis) involvement”, due to evidence suggesting a continuum between arterial, capillary and vein involvement in PAH. 


\section{Introduction}

The main objectives of our Task Force were to reassess haemodynamic definitions and the clinical classification of pulmonary hypertension $(\mathrm{PH})$.

Regarding definitions, we addressed two questions:

1) Should we redefine $\mathrm{PH}$ and pre-capillary $\mathrm{PH}$ ?

2) Should exercise $\mathrm{PH}$ be reintroduced as part of the $\mathrm{PH}$ definition?

The other topic was to update the clinical classification, adopting some basic principles: 1) to maintain the general architecture of the current classification of $\mathrm{PH}$ for adults and children, 2) to provide only relevant modifications, and 3) to simplify the core of the classification

\section{Haemodynamic definitions \\ Definition of $\mathrm{PH}$}

In 1961, a report of the World Health Organization (WHO) Expert Committee on Chronic Cor Pulmonale mentioned clearly that the mean pulmonary arterial pressure (mPAP) does not normally exceed $15 \mathrm{mmHg}$ when the subject is at rest in a lying position, and that the value was little affected by age and never exceeded $20 \mathrm{mmHg}$ [1].

Since the 1st World Symposium on Pulmonary Hypertension (WSPH) organised by the WHO in Geneva in 1973, PH has been defined as mPAP $\geqslant 25 \mathrm{mmHg}$ measured by right heart catheterisation (RHC) in the supine position at rest [2]. The Geneva WHO meeting was devoted to primary $\mathrm{PH}$, a severe form of $\mathrm{PH}$, some years after an outbreak related to the intake of the anorexic drug aminorex [3]. In the report of the meeting, it was recognised that this upper limit of normal mPAP of $25 \mathrm{mmHg}$ was somewhat empirical and arbitrarily defined [2]. However, this conservative cut-off value allowed physicians to discriminate severe $\mathrm{PH}$ due to primary $\mathrm{PH}$ from other forms of $\mathrm{PH}$ (mainly due to lung diseases) characterised by a lower mPAP. This definition remained unchanged during the subsequent WSPH meetings from 1998 to 2013 [4-6], at least in part to preclude potential overdiagnosis and overtreatment of $\mathrm{PH}$.

What is actually the upper limit of normal mPAP?

In 2009, Kovacs et al. [7] analysed all available data obtained by RHC studies in healthy individuals to determine normal values of mPAP at rest and exercise. Data from 1187 normal subjects from 47 studies were analysed. mPAP at rest was $14.0 \pm 3.3 \mathrm{mmHg}$; this value was independent of sex and ethnicity, and was only slightly influenced by age and posture. Considering this mPAP of $14 \mathrm{mmHg}$, two standard deviations would suggest $\mathrm{mPAP}>20 \mathrm{mmHg}$ as above the upper limit of normal (i.e. above the 97.5th percentile). This definition is, therefore, no longer arbitrary, but based on a scientific approach.

A value of MPAP used in isolation is not accurate enough to characterise a clinical condition

Whatever the mPAP cut-off value considered for defining $\mathrm{PH}(\geqslant 25$ or $>20 \mathrm{mmHg}$ ), it is important to emphasise that this value used in isolation cannot characterise a clinical condition and does not define the pathological process per se. PAP elevation may indeed have several different causes with different management and outcomes, including increase in cardiac output (CO), left-to-right cardiac shunts, elevation of pulmonary arterial wedge pressure (PAWP) in left heart disease (LHD) and hyperviscosity. This abnormal elevation may also be due to pulmonary vascular disease (PVD) associated with structural changes of small pulmonary arteries. In the present clinical classification of $\mathrm{PH}$, pre-capillary $\mathrm{PH}$ concerns patients from groups 1, 3 and 4, some patients from group 5, and rarely patients from group 2 with combined pre- and post-capillary $\mathrm{PH}$.

To identify pre-capillary PH suggesting the presence of PVD, an above normal elevation of pulmonary vascular resistance should be included in the definition

Including pulmonary vascular resistance $(\mathrm{PVR}=(\mathrm{mPAP}-\mathrm{PAWP}) / \mathrm{CO})$ in the definition of pre-capillary $\mathrm{PH}$ is essential, allowing discrimination of elevation of PAP due to PVD from those due to elevation of PAWP or due to high CO. Since the 3rd WSPH held in 2003, pre-capillary PH of group 1 (pulmonary arterial hypertension $(\mathrm{PAH})$ ) has been defined by the presence of $\mathrm{mPAP} \geqslant 25 \mathrm{mmHg}$ with a normal PAWP $\leqslant 15 \mathrm{mmHg}$ and elevated PVR $\geqslant 3$ Wood Units (WU) [4-6]. This cut-off value of PVR $\geqslant 3 \mathrm{WU}$ is also quite arbitrary since some recent data suggest that PVR $>2$ WU could be also considered abnormal [6]. In this sense, the use of a cut-off value of PVR $\geqslant 3 \mathrm{WU}$ is conservative, suggesting the presence of a manifest pre-capillary $\mathrm{PH}$. This value of PVR $\geqslant 3 \mathrm{WU}$ is considered clinically relevant in different clinical situations, suggesting the presence of a significant PVD, e.g. it is already used as the threshold value for which the correction of congenital systemic-to-pulmonary shunts becomes questionable [8]. Moreover, it has been shown that elevated PVR $\geqslant 3 \mathrm{WU}$ was associated with a poor survival after heart transplantation [9]. During the 6th WSPH in 2018, for patients of group 2, the Task Force on PH due to LHD recommended 
a PVR cut-off value $\geqslant 3 \mathrm{WU}$ to define patients with a pre-capillary component [10], so-called combined pre- and post-capillary $\mathrm{PH}$, that is associated with a worse prognosis.

We propose including PVR $\geqslant 3 \mathrm{WU}$ not only in the definition of pre-capillary $\mathrm{PH}$ of group 1, but also in the definition of all forms of pre-capillary $\mathrm{PH}$.

In patients with $\mathrm{PH}$ due to chronic obstructive pulmonary disease, those with severe $\mathrm{PH}(>40 \mathrm{mmHg})$ have a marked increase in PVR (around $10 \mathrm{WU}$ ); more often these patients have a mild PH (mPAP 20$30 \mathrm{mmHg}$ ), associated with lower PVR but remaining generally $>3 \mathrm{WU}$ [11], and this is also the case for patients with idiopathic pulmonary fibrosis [12]. In these different chronic lung diseases, even a modest elevation in mPAP (20-29 $\mathrm{mmHg}$ ) was associated with a poor prognosis [13].

In chronic thromboembolism (group 4), a large international registry reported haemodynamic findings of severe pre-capillary PH with a mPAP of $47 \mathrm{mmHg}$ and a mean PVR of $8.9 \mathrm{WU}$ [14]. In this setting, even in patients with mild elevation of mPAP $(20-24 \mathrm{mmHg})$, PVR is generally $>3 \mathrm{WU}$.

\section{Outcome of patients with PVD and mPAP 21-24 $\mathrm{mmHg}$}

Accumulating data indicate that many patients with PVD associated with an increase in mPAP but below the former threshold value defining $\mathrm{PH}(\geqslant 25 \mathrm{mmHg})$ are at risk of disease progression.

In systemic sclerosis, outcome data of patients with mPAP at diagnosis between 21 and $24 \mathrm{mmHg}$ have been recently published. In 2013, a single-centre cohort study of 228 patients with systemic sclerosis who underwent RHC for suspicion of $\mathrm{PH}$ was reported [15]. mPAP 21-24 mmHg was documented in 86 patients at baseline; of these, 38 underwent a second RHC during the follow-up (median follow-up $48 \pm 35$ months) and 16 of these (42\%) developed overt PH (mPAP $\geqslant 25 \mathrm{mmHg}$ ). The mean mPAP and PVR at baseline of these 16 patients was $22 \pm 2 \mathrm{mmHg}$ and $2.9 \pm 0.6 \mathrm{WU}$, respectively; at follow-up, mean $\mathrm{mPAP}$ and PVR increased to $31 \pm 6 \mathrm{mmHg}$ and $6.9 \pm 1.7 \mathrm{WU}$, respectively. Patients with so-called borderline $\mathrm{mPAP}$ at diagnosis were more likely to develop overt $\mathrm{PAH}$ than patients with $\mathrm{mPAP} \leqslant 20 \mathrm{mmHg}$ $(\mathrm{p}<0.001$; hazard ratio (HR) 3.7). Incident development of PAH was not benign in this cohort, with five deaths during follow-up despite the subsequent introduction of dual oral combination therapy and/or i.v. prostacyclin.

More recently, a two-centre cohort study identified 21 patients with systemic sclerosis and a mPAP at baseline of 21-24 mmHg [16]; these patients underwent a second RHC with a median follow-up of 3 years. At baseline, mean mPAP and PVR were $22 \pm 1 \mathrm{mmHg}$ and $2.3 \pm 0.8 \mathrm{WU}$, respectively. At follow-up, mPAP and PVR increased to $25 \pm 4 \mathrm{mmHg}$ and $3.2 \pm 1.6 \mathrm{WU}$, respectively. Among them, seven patients (33\%) developed overt $\mathrm{PH}$ (three $\mathrm{PAH}$, three pre-capillary $\mathrm{PH}$ associated with interstitial lung disease and one PH due to LHD) (J.G. Coghlan, Cardiology Dept, Royal Free Hospital, London, UK; personal communication).

In 2017, an Austrian group [17] published a series of 547 patients with unexplained dyspnoea and/or at risk of $\mathrm{PH}$ who underwent RHC. Manifest $\mathrm{PH}$ (mPAP $\geqslant 25 \mathrm{mmHg}$ ) was confirmed in 290 patients, borderline PH (mPAP 21-24 mmHg) in 64 cases and 193 cases were considered as "normal" with mPAP $\leqslant 20 \mathrm{mmHg}$; among them, 137 patients were defined as "lower normal" with $\mathrm{mPAP} \leqslant 15 \mathrm{mmHg}$. The median follow-up time of this cohort was 45.9 months; overall 161 patients (29\%) died during the follow-up. In the multivariate model, considering age and comorbidities, both borderline $\mathrm{PH}$ and manifest $\mathrm{PH}$ were significantly associated with poor survival compared with the "lower normal" group with HR 2.37 (95\% CI 1.14-4.97; $\mathrm{p}=0.022$ ) and HR 5.05 (95\% CI 2.79-9.12; $\mathrm{p}<0.001$ ), respectively. At baseline, the group with mPAP 21-24 mmHg had a median PVR of $2.7 \mathrm{WU}$ and $36 \%$ of these patients had PVR $>3 \mathrm{WU}$.

Another instance where pre-capillary PH can be diagnosed at an earlier stage is chronic thromboembolism, as in this setting exercise limitation can occur in the absence of overt $\mathrm{PH}$ at rest due to the increase in deadspace ventilation resulting in a decreased ventilatory efficiency. Recently, two cohorts of 42 and 23 patients, respectively, have been reported with extensive persistent thromboembolic occlusions but without $\mathrm{PH}[18,19]$. At diagnosis, mPAP was $15-24 \mathrm{mmHg}$ and PVR was 2-3 WU. These patients underwent pulmonary endarterectomy (PEA) and experienced significant improvement in WHO Functional Class, exercise capacity and quality of life, with no in-hospital mortality at 6 months. This form of chronic thromboembolism corresponded to $4 \%$ and $7 \%$ of the overall population treated with PEA in these two centres.

Summary and perspectives

A mPAP of $20 \mathrm{mmHg}$ should be considered as the upper limit of normal value. This new definition has been recently proposed by others [20-22]. However, this abnormal elevation of MPAP in isolation is not sufficient to define PVD as it can be due to an increase in CO or PAWP. 
Pre-capillary $\mathrm{PH}$ is best defined by the concomitant presence of $\mathrm{mPAP}>20 \mathrm{mmHg}$, PAWP $\leqslant 15 \mathrm{mmHg}$ and PVR $\geqslant 3 \mathrm{WU}$ (table 1), emphasising the need for RHC with mandatory measurement of $\mathrm{CO}$ and accurate measurement of PAWP.

For many years, the diagnosis of $\mathrm{PH}$ was based on an arbitrary value of mPAP $\geqslant 25 \mathrm{mmHg}$, probably because of understandable concern about overdiagnosis and overtreatment. Actually, the main cause of overdiagnosis and treatment of pre-capillary $\mathrm{PH}$ is the failure to confirm the diagnosis by RHC.

Conversely, the other side of this dilemma could be to undertreat some patients with abnormal elevation of PAP but not meeting the classical definition of $\mathrm{PH}$. Today, there is growing evidence that in some PVDs (mainly PAH associated with systemic sclerosis, chronic thromboembolism and chronic lung diseases) patients with even a modest elevation in mPAP (21-24 $\mathrm{mmHg}$ ) are symptomatic with exercise limitation and may have poor outcome. Nevertheless, a change in the haemodynamic definition of $\mathrm{PH}$ due to PVDs does not imply treating these additional patients, but highlights the importance of close monitoring in this population. Prospective trials are required to determine whether this $\mathrm{PH}$ population might benefit from specific management.

\section{Definition of exercise $\mathrm{PH}$}

In 2004, $\mathrm{PH}$ was defined as resting $\mathrm{mPAP}>25 \mathrm{mmHg}$ or exercise $\mathrm{mPAP}>30 \mathrm{mmHg}$ [8]. At the 4th WSPH in 2008, however, the "exercise" part of the definition was removed [23]. This was largely due to uncertainties concerning the interrelationships between normal ageing, $\mathrm{CO}$ changes with exercise and pulmonary vascular physiology. This question was revisited again at the 6th WSPH in 2018.

Why might exercise $\mathrm{PH}$ be relevant?

A rise in resting $\mathrm{PH}$ pressure is a late event in the natural history of PVDs, because of microvascular "reserves". PAP rises only when $\geqslant 50 \%$ of the microcirculation has been lost [24]. Much effort has been directed towards detecting PVD at an earlier (and potentially more treatable) stage. Intuitively, "unmasking" PVD by increasing CO to demonstrate increased resistance is a logical idea. Furthermore, $\mathrm{PH}$ patients first develop symptoms on exercise.

A number of studies have tried to unmask PVD by "stressing" the pulmonary circulation, by lung flow redistribution with upright posture [25] or by increasing CO [26]. This has led to the concept of "multipoint mPAP-CO" curves, where the rate of rise of mPAP with increasing CO has been informative (figure 1). In general, $\mathrm{mPAP}$ rises by $\geqslant 1 \mathrm{mmHg}$ per litre of $\mathrm{CO}$ in normal subjects; PVD patients have a rise of $\geqslant 3 \mathrm{mmHg}$ per litre of $\mathrm{CO}$, reflecting increased resistance [27]. Generating such data is, however, challenging as exercise RHC measurements are time consuming, difficult, and potentially complicated by errors due to rapid respiratory cycles and inaccuracies in exercise CO and PAWP measures. Thus, generating mPAP-CO graphs for individual patients is impractical as a clinical routine.

\section{Why might defining exercise $\mathrm{PH}$ and PAH be difficult?}

A number of variables impact on the "normal" change of mPAP with exercise, which in turn complicates

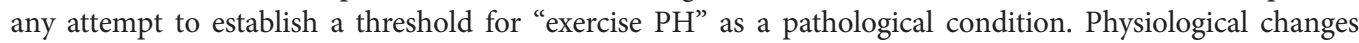
occur with normal ageing [7] and mPAP also does rise with increasing CO; therefore in subjects (e.g. elite

TABLE 1 Haemodynamic definitions of pulmonary hypertension (PH)

\begin{tabular}{|c|c|c|}
\hline Definitions & Characteristics & Clinical groups ${ }^{\#}$ \\
\hline Pre-capillary PH & $\begin{array}{c}\mathrm{mPAP}>20 \mathrm{mmHg} \\
\mathrm{PAWP} \leqslant 15 \mathrm{mmHg} \\
P V R \geqslant 3 \mathrm{WU}\end{array}$ & $1,3,4$ and 5 \\
\hline Isolated post-capillary PH (IpcPH) & $\begin{array}{c}\mathrm{mPAP}>20 \mathrm{mmHg} \\
\mathrm{PAWP}>15 \mathrm{mmHg} \\
\text { PVR }<3 \mathrm{WU}\end{array}$ & 2 and 5 \\
\hline Combined pre- and post-capillary PH (CpcPH) & $\begin{array}{c}\mathrm{mPAP}>20 \mathrm{mmHg} \\
\mathrm{PAWP}>15 \mathrm{mmHg} \\
P V R \geqslant 3 \mathrm{WU}\end{array}$ & 2 and 5 \\
\hline
\end{tabular}

mPAP: mean pulmonary arterial pressure; PAWP: pulmonary arterial wedge pressure; PVR: pulmonary vascular resistance; WU: Wood Units. " ${ }^{\text {: }}$ group 1: $\mathrm{PAH}$; group 2: $\mathrm{PH}$ due to left heart disease; group $3: \mathrm{PH}$ due to lung diseases and/or hypoxia; group 4: $\mathrm{PH}$ due to pulmonary artery obstructions; group 5 : $\mathrm{PH}$ with unclear and/or multifactorial mechanisms. 


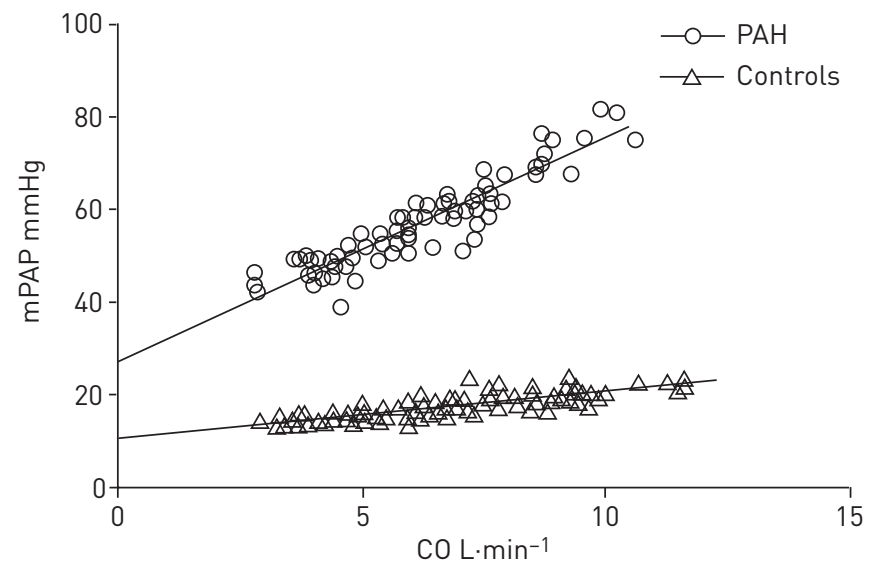

FIGURE 1 The slope of the mean pulmonary arterial pressure (mPAP)-cardiac output (CO) relationship is different in normal control versus pulmonary arterial hypertension (PAH) subjects. Reproduced and modified from [26] with permission.

athletes) who can raise their $\mathrm{CO}$ to $30-40 \mathrm{~L} \cdot \mathrm{min}^{-1}$ at peak exercise, mPAP can exceed previous "upper limits" of normal [28]. The greatest difficulty, however, is in using exercise to deduce the presence of PVD, because exercise also causes a rise in PAWP. Thus, if PVR $=(\mathrm{mPAP}-\mathrm{PAWP}) / \mathrm{CO}$, one must measure exercise PAWP to deduce the pathogenesis of an abnormally high exercise-related PAP. As LHD is the commonest cause of resting $\mathrm{PH}$ and left atrial pressure rises abnormally with exercise in subjects with LHD, measuring changes in PAWP (or left atrial pressure) with exercise becomes the critical determinant for assessing PVR, in breathless patients with exercise PH.

This lack of diagnostic discrimination power (whether exercise PH is due to LHD or to PVD) has been explored by Herve et al. [29]. Although total pulmonary resistance $>3 \mathrm{mmHg}$ per litre of CO distinguished healthy controls from those with LHD or PVD, it was impossible to distinguish LHD from PVD patients with confidence (figure 2). It should be noted that accurate measurement of exercise PAWP is technically challenging, related to the exaggerated respiratory swings in PAWP and in part to difficulties in "wedging" a balloon catheter adequately during vigorous exertion.

\section{Summary and perspectives}

Although there is intuitive appeal to measuring exercise haemodynamics to detect PVD at an earlier stage than can be revealed by measurements at rest, too many uncertainties persist to allow the reintroduction of a clinically useful definition of exercise PH. More information is required concerning normal changes

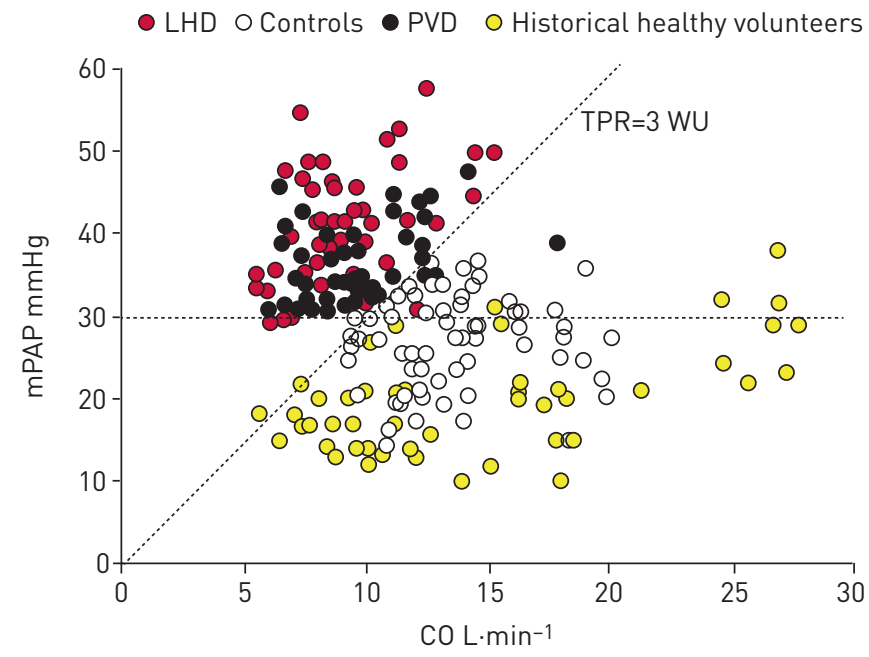

FIGURE 2 Knowledge of the mean pulmonary arterial pressure (mPAP)-cardiac output (CO) relationship does not allow distinction between left heart disease (LHD) and pulmonary vascular disease (PVD) patients; knowledge of exercise pulmonary arterial wedge pressure is also required. TPR: total pulmonary resistance; WU: Wood Units. Reproduced from [29] with permission. 
with ageing, high CO and especially about distinguishing exercise-elated changes in PAWP (due to LHD) from changes due to PVD. We believe that these will be fruitful areas for future investigation.

\section{Updated clinical classification of PH}

The general purpose of clinical classification of $\mathrm{PH}$ is to categorise clinical conditions associated with $\mathrm{PH}$ based on similar pathophysiological mechanisms, clinical presentation, haemodynamic characteristics and therapeutic management. A comprehensive and simplified version of the clinical classification of $\mathrm{PH}$ in children and adults is presented in table 2. For patients with PAH associated with congenital heart disease, the four subgroups (Eisenmenger syndrome, left-to-right shunts, coincidental or small defects and post-operative/closed defects) remain the same [30] as the indications for defect closure (see the Task Force article in this issue of the European Respiratory Journal [31]). The updates of groups 2, 3 and 4 are presented in the respective Task Force articles in this issue of the European Respiratory Journal [10, 32, 33].

Update of group 1: $\mathrm{PAH}$

Group 1.3: Drug- and toxin-induced PAH

We propose simplifying the characterisation of PAH associated with drugs and toxins into two subgroups to help physicians to identify drugs requiring specific surveillance. "Definite association" includes drugs with data based on outbreaks, epidemiological case-control studies or large multicentre series. "Possible association" is suggested by multiple case series or cases with drugs with similar mechanisms of action. Based on recent data, the association of PAH with two drugs and toxins (amphetamines/ methamphetamines and dasatinib) is now considered definite (table 3).

ZAMANIAN et al. [34] reported a large series of 90 cases of $\mathrm{PAH}$ associated with methamphetamineassociated PAH; these subjects were less likely to be female, had more haemodynamic compromise at diagnosis and had poorer outcomes than IPAH. This analysis confirmed an association between

\section{TABLE 2 Updated clinical classification of pulmonary hypertension (PH)}

\section{$1 \mathrm{PAH}$}

1.1 Idiopathic PAH

1.2 Heritable PAH

1.3 Drug- and toxin-induced PAH (table 3)

1.4 PAH associated with:

1.4.1 Connective tissue disease

1.4.2 HIV infection

1.4.3 Portal hypertension

1.4.4 Congenital heart disease

1.4.5 Schistosomiasis

1.5 PAH long-term responders to calcium channel blockers (table 4)

1.6 PAH with overt features of venous/capillaries (PVOD/PCH) involvement (table 5)

1.7 Persistent $\mathrm{PH}$ of the newborn syndrome

\section{$2 \mathrm{PH}$ due to left heart disease}

2.1 $\mathrm{PH}$ due to heart failure with preserved LVEF

2.2 $\mathrm{PH}$ due to heart failure with reduced LVEF

2.3 Valvular heart disease

2.4 Congenital/acquired cardiovascular conditions leading to post-capillary PH

$3 \mathrm{PH}$ due to lung diseases and/or hypoxia

3.1 Obstructive lung disease

3.2 Restrictive lung disease

3.3 Other lung disease with mixed restrictive/obstructive pattern

3.4 Hypoxia without lung disease

3.5 Developmental lung disorders

$4 \mathrm{PH}$ due to pulmonary artery obstructions (table 6)

4.1 Chronic thromboembolic $\mathrm{PH}$

4.2 Other pulmonary artery obstructions

$5 \mathrm{PH}$ with unclear and/or multifactorial mechanisms (table 7)

5.1 Haematological disorders

5.2 Systemic and metabolic disorders

5.3 Others

5.4 Complex congenital heart disease

PAH: pulmonary arterial hypertension; PVOD: pulmonary veno-occlusive disease; $\mathrm{PCH}$ : pulmonary capillary haemangiomatosis; LVEF: left ventricular ejection fraction. 
TABLE 3 Updated classification of drugs and toxins associated with PAH

Definite Possible

Aminorex

Fenfluramine

Dexfenfluramine

Benfluorex

Methamphetamines

Dasatinib

Toxic rapeseed oil
Cocaine

Phenylpropanolamine

L-tryptophan

St John's wort

Amphetamines

Interferon- $\alpha$ and $-\beta$

Alkylating agents

Bosutinib

Direct-acting antiviral agents against hepatitis $\mathrm{C}$ virus Leflunomide

Indirubin (Chinese herb Qing-Dai)

methamphetamine/amphetamine use and PAH-related hospitalisation (relative risk 2.64, 95\% CI 2.18-3.2; $\mathrm{p}<0.001)$. Interestingly, pathological assessment demonstrated characteristic vascular changes similar to IPAH, including angiomatoid plexiform lesions, but also proliferative capillaries, as described in pulmonary capillary haemangiomatosis $(\mathrm{PCH})$ or pulmonary veno-occlusive disease (PVOD). Dasatinib is a second-generation tyrosine kinase inhibitor and has been reported to be associated with PAH; the lowest estimate of incident PAH occurring in patients exposed to dasatinib in France was 0.45\% [35]. Dasatinib-induced PAH frequently improves after discontinuation, but persists in over one-third of patients $[35,36]$.

Over the last 5 years, new drugs have been identified or suspected as potential risk factors for PAH. Several cases of deterioration or relapse of dasatinib-associated PAH after bosutinib initiation have been reported [37-39]; these cases were also characterised by an improvement of PAH after withdrawal of bosutinib. Cases of severe portopulmonary hypertension have occurred with novel strategies of direct-acting antivirals, including sofosbuvir for hepatitis C virus infection [40, 41]. Leflunomide, a disease-modifying antirheumatic drug, has been associated with several cases of PAH [42-44]. Recently, cases of potentially reversible PAH associated with natural indigo (Qing-Dai), an unapproved Chinese herbal drug, have been reported from the Japan Pulmonary Hypertension Registry [45, 46]. The active pharmaceutical ingredient of Qing-Dai is indirubin, which could induce apoptosis of pulmonary endothelial cells in vitro [46].

\section{Group 1.5: PAH long-term responders to calcium channel blockers}

Although remodelling of small pulmonary arteries is the main pathological finding in PAH, pulmonary vasoconstriction also plays an important role in $\mathrm{PAH}$ pathophysiology, particularly in vasoreactive patients.

In a series of 64 patients published in 1992, Rich et al. [47] reported that patients with an acute vasodilator response to calcium channel blockers (CCBs) had dramatically improved survival when treated with long-term CCBs. In 2005, SiтBON et al. [48] demonstrated in a large series of $557 \mathrm{PH}$ patients that acute vasodilator response may be observed in $12.5 \%$ of idiopathic PAH (IPAH), and overall $6.8 \%$ of patients have a long-term clinical and haemodynamic improvement on CCBs. This study identified the best criteria to identify acute vasodilator response, i.e. a reduction of $\mathrm{mPAP} \geqslant 10 \mathrm{mmHg}$ to reach an absolute value of mPAP $\leqslant 40 \mathrm{mmHg}$ with an increased or unchanged CO. For vasoreactivity testing, inhaled nitric oxide at $10-20 \mathrm{ppm}$ is the preferred agent, but i.v. epoprostenol, i.v. adenosine or inhaled iloprost can be used as alternatives (table 4). Long-term response to CCBs was defined by clinical

TABLE 4 Definitions of acute and long-term response

Acute pulmonary vasoreactivity ${ }^{\#}$ for patients with idiopathic, hereditable or drug-induced PAH

Long-term response to CCBs
Reduction of $\mathrm{mPAP} \geqslant 10 \mathrm{mmHg}$ to reach an absolute value of $\mathrm{mPAP} \leqslant 40 \mathrm{mmHg}$ Increased or unchanged cardiac output

New York Heart Association Functional Class I/II

With sustained haemodynamic improvement (same or better than achieved in the acute test) after at least 1 year on CCBs only

$\mathrm{PAH}$ : pulmonary arterial hypertension; mPAP: mean pulmonary arterial pressure; CCB: calcium channel blocker. ${ }^{\#}$ : nitric oxide (10-20 ppm) is recommended for performing vasoreactivity testing, but i.v. epoprostenol, i.v. adenosine or inhaled iloprost can be used as alternatives. 
improvement (New York Heart Association Functional Class I or II) and sustained haemodynamic improvement after at least 1 year on CCBs only (same or better than achieved in the acute test and usually to obtain $\mathrm{mPAP}<30 \mathrm{mmHg}$ with an increased or normal $\mathrm{CO}$ ) (table 4). Pulmonary vasoreactivity testing for identification of patients suitable for CCB treatment is recommended only for patients with IPAH, heritable PAH or drug-induced PAH. In all other forms of PAH and $\mathrm{PH}$ the results can be misleading and long-term responders are rare [49].

Pathophysiology of PAH with vasoreactivity is largely unknown. Recently, Hemnes and co-workers have shown that PAH with vasoreactivity was characterised by a specific blood signature (microarray of cultured lymphocytes) and different gene variants (whole exome sequencing) compared with IPAH [50, 51]. These results suggest a specific entity with a distinct clinical course, characterised by significantly better prognosis, unique management and different pathophysiology (table 2).

\section{Group 1.6: PAH with overt features of venous/capillaries (PVOD/PCH) involvement}

Significant pulmonary venous and/or capillary involvement has been reported in many conditions which are known causes of $\mathrm{PAH}$, such as systemic sclerosis. In the previous classification, $\mathrm{PVOD} / \mathrm{PCH}$ was characterised as a distinct subgroup.

$\mathrm{PVOD} / \mathrm{PCH}$ and $\mathrm{PAH}$ share similar causes and associated conditions even if some of them are more frequently associated with more pronounced venous/capillary involvement (table 5). Heritable forms of $\mathrm{PVOD} / \mathrm{PCH}$ have been recognised in consanguineous families with a recessive transmission, due to biallelic mutations in the eukaryotic translation initiation factor $2 \alpha$ kinase 4 (EIF2AK4) gene [52-54]. Occupational exposure to organic solvents, particularly to trichloroethylene, has been associated with the development of pre-capillary PH with significant venous and capillary involvement [55].

Diagnosis of significant pulmonary venous/capillary involvement (PVOD/PCH) may be strongly suspected based on pulmonary function tests (decreased diffusion capacity of the lung for carbon monoxide (DLCO) frequently $<50 \%$ of theoretical values), arterial blood gases (severe hypoxaemia) and high-resolution computed tomography of the chest (septal lines, centrilobular ground-glass opacities/nodules and mediastinal lymph node enlargement) (table 5) $[53,54,56]$. More pronounced pulmonary venous/capillary involvement is associated with a poor prognosis, a limited response to PAH therapy and a risk of pulmonary oedema with these treatments $[53,57]$.

$\mathrm{PAH}$ and PVOD/PCH usually share a broadly similar haemodynamic profile and clinical presentation. Of note, significant pulmonary arterial remodelling has been described in biallelic EIF2AK4 mutation carriers [58] and muscular remodelling of pulmonary septal veins can be observed in BMPR2 (bone morphogenetic protein receptor type 2) mutation carriers [59]. What matters in practice are the clinical consequences of pulmonary venous/capillary involvement in pre-capillary $\mathrm{PH}$. We therefore suggest that $\mathrm{PAH}$ and $\mathrm{PVOD} / \mathrm{PCH}$ belong to a spectrum of PVDs rather than representing two clear-cut distinct entities. We propose including "PAH with overt features of venous/capillaries (PVOD/PCH) involvement" in the revised PAH (group 1) of the updated PH classification (table 2).

Update of group 5: PH with unclear and/or multifactorial mechanisms

Since the basis of our classification system was established in 1998, group 5 has passed through significant changes. Initially describing "disorders directly affecting the pulmonary vasculature", then named "miscellaneous" during the 3rd WSPH in 2003 [60], and finally reaching its current presentation, this group includes forms of $\mathrm{PH}$ with unclear and/or multifactorial mechanisms [30,61]. From the beginning,

TABLE 5 Signs evocative of venous and capillary (pulmonary veno-occlusive disease/pulmonary capillary haemangiomatosis) involvement

\section{Pulmonary function tests}

Chest HRCT
Decreased DLco (frequently $<50 \%$ )

Severe hypoxaemia

$$
\text { Septal lines }
$$

Centrilobular ground-glass opacities/nodules Mediastinal lymph node enlargement

Possible pulmonary oedema

Biallelic EIF2AK4 mutations

Organic solvent (trichloroethylene)

DLCO: diffusing capacity of the lung for carbon monoxide; HRCT: high-resolution computed tomography; $\mathrm{PAH}$ : pulmonary arterial hypertension. 
TABLE 6 Pulmonary hypertension (PH) due to pulmonary artery obstructions

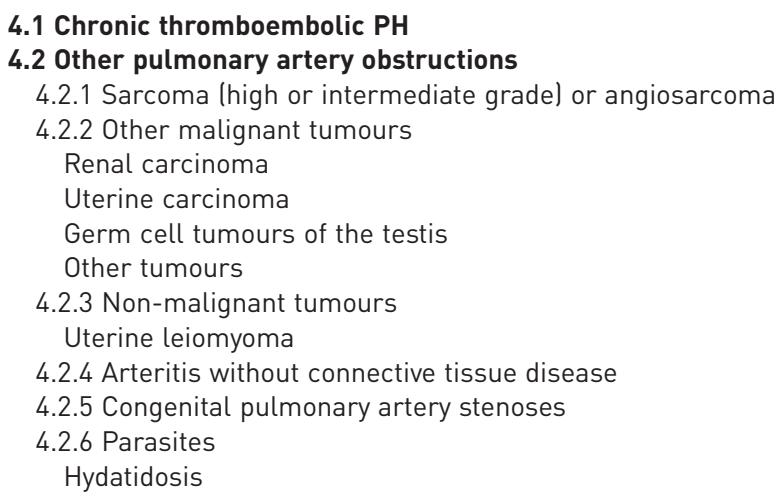

this group has represented less-studied forms of $\mathrm{PH}$, in comparison with other groups; nevertheless, many of the $\mathrm{PH}$ forms currently in group 5 represent a significant part of the yet unrecognised worldwide burden of $\mathrm{PH}[62]$.

One of the central characteristics of the clinical conditions included in group 5 is that there is no identified predominant mechanism driving the development of $\mathrm{PH}$ and there may be multiple pathophysiological phenomena involved in this process (table 7). In this update of the classification, changes were considered only for the subtypes in which a definite relocation was supported by the available literature.

\section{Group 5.1: Haematological disorders}

Chronic haemolytic anaemia is clearly associated with an increased risk of PH [63]. Since the 5th WSPH in 2013, little has been added to the current understanding of the numerous presentations of $\mathrm{PH}$ in sickle cell disease (SCD). However, it is clear that in this setting $\mathrm{PH}$ is frequently multifactorial, including elevated CO, LHD, thromboembolic disease, altered blood viscosity and PVD due to endothelial dysfunction, mainly due to nitric oxide depletion [64-67]. More recently, restrictive cardiomyopathy has been better recognised and described in clinical and experimental studies [68]. These data reinforce the utmost importance of this particular form of $\mathrm{PH}$ and the need for continuous investigation in this field $[64,65]$. In addition, over recent years, significant data have been generated regarding another important chronic haemolytic anaemia, i.e. $\beta$-thalassaemia. A better understanding about the risk factors for major complications of the disease, including $\mathrm{PH}$, has been derived from significant cohorts [69]. Furthermore, DerCHi et al. [70] evaluated the prevalence of $\mathrm{PH}$ through invasive haemodynamic evaluation, similarly to what has been done in SCD [71-73]. In their cohort of 1309 patients that underwent screening evaluation, pre-capillary $\mathrm{PH}$ was confirmed in $2.1 \%$ of the cases, while a post-capillary profile was found in $0.3 \%$ [ 70$]$. Older age and splenectomy were clear risk factors associated with $\mathrm{PH}$. Although this study provided important information regarding the significance of $\mathrm{PH}$ in this clinical condition, more data concerning the histopathology of vascular involvement as well as about pathophysiological mechanisms of $\mathrm{PH}$ development in these patients are still needed to better address potential management strategies.

TABLE 7 Pulmonary hypertension with unclear and/or multifactorial mechanisms

\subsection{Haematological disorders \\ 5.2 Systemic and metabolic disorders}

\subsection{Others}
5.4 Complex congenital heart disease

Chronic haemolytic anaemia Myeloproliferative disorders

Pulmonary Langerhans cell histiocytosis

Gaucher disease

Glycogen storage disease

Neurofibromatosis

Sarcoidosis

Chronic renal failure with or without haemodialysis Fibrosing mediastinitis

See the Task Force article by RosenzWeig et al. [31] in this issue of the European Respiratory Journal 
Splenectomy deserves particular discussion. Following the first association of splenectomy and PH [74], it was not clear whether it represented a risk factor or a particular condition. Since then, splenectomy has been associated with the development of $\mathrm{PH}$ in many haematological conditions, as in the aforementioned $\beta$-thalassaemia $[69,70]$. Most importantly, it has been strongly associated with the development of chronic thromboembolic PH [75]. Nevertheless, no other particular phenotype or change in clinical behaviour has been associated with the presence of splenectomy, suggesting that it should be better considered as a risk factor for $\mathrm{PH}$ instead of a particular condition deserving a specific classification.

Group 5.2: Systemic and metabolic disorders

It is important to emphasise that the concept supporting the classification of a clinical condition with systemic manifestations and a clear risk for $\mathrm{PH}$ into group 5 is, again, the lack of robust data allowing a definite recognition of predominant pathophysiological mechanisms, or describing the histopathological findings or yet, describing management strategies. For this reason, several conditions have been classified in this group, including sarcoidosis, lymphangioleiomyomatosis (LAM), pulmonary Langerhans cell histiocytosis, thyroid disorders, Gaucher disease, glycogen storage disease and neurofibromatosis

Regarding LAM, a recent screening study [76], in a significant cohort of more than 100 LAM patients, reinforced that PH in LAM is usually mild, as previously described [77]. From six patients (5.7\%) presenting with pre-capillary $\mathrm{PH}$, none had $\mathrm{mPAP}>30 \mathrm{mmHg}$. Moreover, the presence of $\mathrm{PH}$ was associated with poor pulmonary function, suggesting that the rise in pulmonary pressure is associated with parenchymal involvement, which was further reinforced by a more recent echocardiographic study [78]. Based on these findings, $\mathrm{PH}$ in LAM seem to be better classified together with other parenchymal lung diseases, in group 3.

Sarcoidosis is a more challenging situation, given the fact that $\mathrm{PH}$ might develop as a consequence of significantly different factors, from parenchymal lung disease to extrinsic compression of pulmonary vessels, direct myocardial involvement or even granulomatous arteriopathy [79]. Significant lung parenchymal disease is a highly prevalent condition in patients with sarcoidosis-associated $\mathrm{PH}[80,81]$, although the presence of left ventricular dysfunction cannot be neglected [80]. It is difficult, however, to solely consider lung parenchymal involvement to reclassify sarcoidosis, given the multiplicity of other factors yet to be clarified, including the different histopathological pattern of the pulmonary vessels commonly seen in sarcoidosis, with granuloma formation in some cases [79], as opposed to other diseases in group 3. While these features are better studied, sarcoidosis remains classified into group 5.

There is a strong rationale for the concomitance of thyroid diseases and $\mathrm{PH}$, from autoimmunity to the presence of high or low CO, left ventricular dysfunction, or even an angioproliferation profile. The prevalence of thyroid disorders is increased in patients with $\mathrm{PAH}[82,83]$; furthermore, the level of thyroid dysfunction is also associated with prognosis in this setting [84]. Nevertheless, similarly to splenectomy, the presence of thyroid dysfunction does not necessarily characterise a specific clinical condition; it behaves more like a risk factor or a comorbidity that should be specifically controlled during the course of $\mathrm{PH}$ management. Until novel data prove otherwise, it was a consensus to withdraw thyroid disorders from the classification as a specific entity and better discuss their role as risk factors and/or associated comorbidities.

Many different conditions associated with $\mathrm{PH}$ still need better designed studies that add to the understanding of disease development. We propose that changes be made only after the generation of robust data to support such reclassification.

\section{Conclusions}

This Task Force first revisited the definition of $\mathrm{PH}$, suggesting a new pressure level to define an abnormal elevation in the mPAP $>20 \mathrm{mmHg}$ and the need for PVR $\geqslant 3 \mathrm{WU}$ to define the presence of pre-capillary $\mathrm{PH}$. Furthermore, the Task Force proposed to simplify the core of the clinical classification of PH (table 2) which has been developed in additional tables. The two main changes in group 1 (PAH) include 1) the designation of a subgroup "PAH long-term responders to CCBs" and 2) the inclusion of the subgroup "PAH with overt features of venous/capillaries (PVOD/PCH) involvement". Group 5 ( $\mathrm{PH}$ with unclear and/or multifactorial mechanisms) was simplified with 1) the removal of splenectomy and thyroid disorders, and 2) the classification of LAM-associated PH together with other parenchymal lung diseases in group 3. Important new insights for groups 2, 3 and 4 have been addressed by the respective Task Forces in this issue of the European Respiratory Journal [10, 32, 33].

Conflict of interest: G. Simonneau reports grants, personal fees and non-financial support from Actelion Pharmaceuticals, Bayer Healthcare, Merck and GSK, outside the submitted work. D. Montani reports grants, personal fees and non-financial support from Actelion Pharmaceuticals, Bayer Healthcare, Merck and GSK, outside the submitted work. D.S. Celermajer is an investigator on two clinical trials sponsored by Actelion. C.P. Denton reports grants and personal fees from Actelion and Roche, grants from GSK, and personal fees from Bayer and Boehringer 
Ingelheim, during the conduct of the study; grants and personal fees from Inventiva and CSL Behring, and personal fees from Leadiant, outside the submitted work. M.A. Gatzoulis reports personal fees for steering committee membership from Actelion Pharmaceuticals, and grants from Actelion Global, Pfizer and GSK, during the conduct of the study. M. Krowka is a steering committee member for PORTICO (Macitentan for Portopulmonary Hypertension Study) which is sponsored by Actelion, outside the submitted work. P.G. Williams received personal fees for advisory board meetings from Aspen SA and GSK, outside the submitted work. R. Souza reports lecture and consultancy fees from Actelion, Bayer, GSK and Pfizer, outside the submitted work.

\section{References}

1 World Health Organization. Chronic cor pulmonale. Report of an expert committee. World Health Organ Tech Rep Ser 1961; 213: 35.

2 Hatano S, Strasser T, eds. Primary Pulmonary Hypertension. Report on a WHO Meeting. Geneva, World Health Organization, 1975.

3 Gurtner HP. Pulmonale Hypertonie nach Appetizuglern. [Pulmonary hypertension following appetite depressants.] Med Welt 1972; 23: 1036-1041.

4 Barst RJ, McGoon M, Torbicki A, et al. Diagnosis and differential assessment of pulmonary arterial hypertension. J Am Coll Cardiol 2004; 43: 40S-47S.

5 Badesch DB, Champion HC, Sanchez MAG, et al. Diagnosis and assessment of pulmonary arterial hypertension. J Am Coll Cardiol 2009; 54: S55-S66.

6 Hoeper MM, Bogaard HJ, Condliffe R, et al. Definitions and diagnosis of pulmonary hypertension. J Am Coll Cardiol 2013; 62: D42-D50.

7 Kovacs G, Berghold A, Scheidl S, et al. Pulmonary arterial pressure during rest and exercise in healthy subjects: a systematic review. Eur Respir J 2009; 34: 888-894.

8 Galiè N, Humbert M, Vachiery J-L, et al. 2015 ESC/ERS Guidelines for the diagnosis and treatment of pulmonary hypertension. Eur Respir J 2015; 46: 903-975.

9 Tedford RJ, Beaty CA, Mathai SC, et al. Prognostic value of the pre-transplant diastolic pulmonary artery pressure-to-pulmonary capillary wedge pressure gradient in cardiac transplant recipients with pulmonary hypertension. J Heart Lung Transplant 2014; 33: 289-297.

10 Vachiéry J-L, Tedford RJ, Rosenkranz S, et al. Pulmonary hypertension due to left heart disease. Eur Respir J 2019; 53: 1801897 .

11 Chaouat A, Bugnet A-S, Kadaoui N, et al. Severe pulmonary hypertension and chronic obstructive pulmonary disease. Am J Respir Crit Care Med 2005; 172: 189-194.

12 Weitzenblum E, Chaouat A, Canuet $\mathrm{M}$, et al. Pulmonary hypertension in chronic obstructive pulmonary disease and interstitial lung diseases. Semin Respir Crit Care Med 2009; 30: 458-470.

13 Bishop JM, Cross KW. Physiological variables and mortality in patients with various categories of chronic respiratory disease. Bull Eur Physiopathol Respir 1984; 20: 495-500.

14 Pepke-Zaba J, Delcroix M, Lang I, et al. Chronic thromboembolic pulmonary hypertension (CTEPH): results from an international prospective registry. Circulation 2011; 124: 1973-1981.

15 Valerio CJ, Schreiber BE, Handler CE, et al. Borderline mean pulmonary artery pressure in patients with systemic sclerosis: transpulmonary gradient predicts risk of developing pulmonary hypertension. Arthritis Rheum 2013; 65: 1074-1084.

16 Coghlan JG, Wolf M, Distler O, et al. Incidence of pulmonary hypertension and determining factors in patients with systemic sclerosis. Eur Respir J 2018; 51: 1701197.

17 Douschan P, Kovacs G, Avian A, et al. Mild elevation of pulmonary arterial pressure as a predictor of mortality. Am J Respir Crit Care Med 2018; 197: 509-516.

18 Taboada D, Pepke-Zaba J, Jenkins DP, et al. Outcome of pulmonary endarterectomy in symptomatic chronic thromboembolic disease. Eur Respir J 2014; 44: 1635-1645.

19 Yildızeli ŞO, Kepez A, Taș S, et al. Pulmonary endarterectomy for patients with chronic thromboembolic disease. Anatol J Cardiol 2018; 19: 273-278.

20 Maron BA, Brittain EL, Choudhary G, et al. Redefining pulmonary hypertension. Lancet Respir Med 2018; 6: $168-170$

21 Maron BA, Wertheim BM, Gladwin MT. Under pressure to clarify pulmonary hypertension clinical risk. Am J Respir Crit Care Med 2018; 197: 423-426.

22 Condliffe R, Kovacs G. Identifying early pulmonary arterial hypertension in patients with systemic sclerosis. Eur Respir J 2018; 51: 1800495.

23 Galiè N, Hoeper MM, Humbert M, et al. Guidelines for the diagnosis and treatment of pulmonary hypertension. Eur Respir J 2009; 34: 1219-1263.

24 Lau EMT, Humbert M, Celermajer DS. Early detection of pulmonary arterial hypertension. Nat Rev Cardiol 2015; 12: $143-155$.

25 Lau EM, Bailey DL, Bailey EA, et al. Pulmonary hypertension leads to a loss of gravity dependent redistribution of regional lung perfusion: a SPECT/CT study. Heart 2014; 100: 47-53.

26 Lau EMT, Vanderpool RR, Choudhary P, et al. Dobutamine stress echocardiography for the assessment of pressure-flow relationships of the pulmonary circulation. Chest 2014; 146: 959-966.

27 Naeije R, Vanderpool R, Dhakal BP, et al. Exercise-induced pulmonary hypertension: physiological basis and methodological concerns. Am J Respir Crit Care Med 2013; 187: 576-583.

28 Reeves J, Dempsey J, Grover R. Pulmonary circulation during exercise. In: Weir EK, Reeves JT, eds. Pulmonary Vascular Physiology and Physiopathology. New York, Marcel Dekker, 1989; pp. 107-133.

29 Herve P, Lau EM, Sitbon O, et al. Criteria for diagnosis of exercise pulmonary hypertension. Eur Respir J 2015; 46: $728-737$.

30 Simonneau G, Gatzoulis MA, Adatia I, et al. Updated clinical classification of pulmonary hypertension. J Am Coll Cardiol 2013; 62: D34-D41.

31 Rosenzweig EB, Abman SH, Adatia I, et al. Paediatric pulmonary arterial hypertension: updates on definition, classification, diagnostics and management. Eur Respir J 2019; 53: 1801916. 
32 Nathan SD, Barbera JA, Gaine SP, et al. Pulmonary hypertension in chronic lung disease and hypoxia. Eur Respir J 2019; 53: 1801914.

33 Kim NH, Delcroix M, Jais X, et al. Chronic thromboembolic pulmonary hypertension. Eur Respir J 2019; 53 : 1801915.

34 Zamanian RT, Hedlin H, Greuenwald P, et al. Features and outcomes of methamphetamine-associated pulmonary arterial hypertension. Am J Respir Crit Care Med 2018; 197: 788-800.

35 Montani D, Bergot E, Günther S, et al. Pulmonary arterial hypertension in patients treated by dasatinib. Circulation 2012; 125: 2128-2137.

36 Weatherald J, Chaumais M-C, Savale L, et al. Long-term outcomes of dasatinib-induced pulmonary arterial hypertension: a population-based study. Eur Respir J 2017; 50: 1700217.

37 Riou M, Seferian A, Savale L, et al. Deterioration of pulmonary hypertension and pleural effusion with bosutinib following dasatinib lung toxicity. Eur Respir J 2016; 48: 1517-1519.

38 Hickey PM, Thompson AAR, Charalampopoulos A, et al. Bosutinib therapy resulting in severe deterioration of pre-existing pulmonary arterial hypertension. Eur Respir J 2016; 48: 1514-1516.

39 Seegobin K, Babbar A, Ferreira J, et al. A case of worsening pulmonary arterial hypertension and pleural effusions by bosutinib after prior treatment with dasatinib. Pulm Circ 2017; 7: 808-812.

40 Renard S, Borentain P, Salaun E, et al. Severe pulmonary arterial hypertension in patients treated for hepatitis C with sofosbuvir. Chest 2016; 149: e69-e73.

41 Savale L, Chaumais M-C, Montani D, et al. Direct-acting antiviral medications for hepatitis C virus infection and pulmonary arterial hypertension. Chest 2016; 150: 256-258.

42 Alvarez PA, Saad AK, Flagel S, et al. Leflunomide-induced pulmonary hypertension in a young woman with rheumatoid arthritis: a case report. Cardiovasc Toxicol 2012; 12: 180-183.

43 Coirier V, Lescoat A, Chabanne C, et al. Pulmonary arterial hypertension in four patients treated by leflunomide. Joint Bone Spine 2018; 85: 761-763.

44 Martinez-Taboada VM, Rodriguez-Valverde V, Gonzalez-Vilchez F, et al. Pulmonary hypertension in a patient with rheumatoid arthritis treated with leflunomide. Rheumatology 2004; 43: 1451-1453.

45 Nishio M, Hirooka K, Doi Y. Chinese herbal drug natural indigo may cause pulmonary artery hypertension. Eur Heart J 2016; 37: 1992.

46 Tamura Y, Furukawa A, Li T, et al. Severe pulmonary arterial hypertension in patients treated by Chinese herb nature indigo: Qing-Dai. Poster presentation at the 6th World Symposium on Pulmonary Hypertension, Nice, 2018; A108.

47 Rich S, Kaufmann E, Levy PS. The effect of high doses of calcium-channel blockers on survival in primary pulmonary hypertension. N Engl J Med 1992; 327: 76-81.

48 Sitbon $\mathrm{O}$, Humbert $\mathrm{M}$, Jaïs $\mathrm{X}$, et al. Long-term response to calcium channel blockers in idiopathic pulmonary arterial hypertension. Circulation 2005; 111: 3105-3111.

49 Montani D, Savale L, Natali D, et al. Long-term response to calcium-channel blockers in non-idiopathic pulmonary arterial hypertension. Eur Heart J 2010; 31: 1898-1907.

50 Hemnes AR, Zhao M, West J, et al. Critical genomic networks and vasoreactive variants in idiopathic pulmonary arterial hypertension. Am J Respir Crit Care Med 2016; 194: 464-475.

51 Hemnes AR, Trammell AW, Archer SL, et al. Peripheral blood signature of vasodilator-responsive pulmonary arterial hypertension. Circulation 2015; 131: 401-409.

52 Eyries M, Montani D, Girerd B, et al. EIF2AK4 mutations cause pulmonary veno-occlusive disease, a recessive form of pulmonary hypertension. Nat Genet 2014; 46: 65-69.

53 Montani D, Girerd B, Jaïs X, et al. Clinical phenotypes and outcomes of heritable and sporadic pulmonary veno-occlusive disease: a population-based study. Lancet Respir Med 2017; 5: 125-134.

54 Hadinnapola C, Bleda M, Haimel M, et al. Phenotypic characterization of EIF2AK4 mutation carriers in a large cohort of patients diagnosed clinically with pulmonary arterial hypertension. Circulation 2017; 136: 2022-2033.

55 Montani D, Lau EM, Descatha A, et al. Occupational exposure to organic solvents: a risk factor for pulmonary veno-occlusive disease. Eur Respir J 2015; 46: 1721-1731.

56 Montani D, Achouh L, Dorfmüller P, et al. Pulmonary veno-occlusive disease: clinical, functional, radiologic, and hemodynamic characteristics and outcome of 24 cases confirmed by histology. Medicine 2008; 87: 220-233

57 Mandel J, Mark EJ, Hales CA. Pulmonary veno-occlusive disease. Am J Respir Crit Care Med 2000; 162: 1964-1973.

58 Nossent EJ, Antigny F, Montani D, et al. Pulmonary vascular remodeling patterns and expression of general control nonderepressible 2 (GCN2) in pulmonary veno-occlusive disease. J Heart Lung Transplant 2018; 37: $647-655$.

59 Ghigna M-R, Guignabert C, Montani D, et al. BMPR2 mutation status influences bronchial vascular changes in pulmonary arterial hypertension. Eur Respir J 2016; 48: 1668-1681.

60 Simonneau G, Galiè N, Rubin LJ, et al. Clinical classification of pulmonary hypertension. J Am Coll Cardiol 2004; 43: $5 \mathrm{~S}-12 \mathrm{~S}$.

61 Simonneau G, Robbins IM, Beghetti M, et al. Updated clinical classification of pulmonary hypertension. $J$ Am Coll Cardiol 2009; 54: S43-S54.

62 Humbert M, Khaltaev N, Bousquet J, et al. Pulmonary hypertension: from an orphan disease to a public health problem. Chest 2007; 132: 365-367.

63 Souza R, Fernandes JJ, Jardim CV, et al. Other causes of PAH (schistosomiasis, porto-pulmonary hypertension and hemolysis-associated pulmonary hypertension). Semin Respir Crit Care Med 2009; 30: 448-457.

64 Fonseca G, Souza R. Pulmonary hypertension in sickle cell disease. Curr Opin Pulm Med 2015; 21: 432-437.

65 Mehari A, Thomas AV, Thomas AN, et al. Review: hemodynamic characteristics and outcomes of sickle cell disease associated pulmonary hypertension. Ethn Dis 2016; 26: 545-552.

66 Tsitsikas DA, Sirigireddy B, Nzouakou R, et al. Safety, tolerability, and outcomes of regular automated red cell exchange transfusion in the management of sickle cell disease. J Clin Apher 2016; 31: 545-550.

67 Gladwin MT, Sachdev V, Jison ML, et al. Pulmonary hypertension as a risk factor for death in patients with sickle cell disease. N Engl J Med 2004; 350: 886-895.

68 Niss O, Quinn CT, Lane A, et al. Cardiomyopathy with restrictive physiology in sickle cell disease. JACC Cardiovasc Imaging 2016; 9: 243-252. 
Teawtrakul N, Jetsrisuparb A, Pongudom S, et al. Epidemiologic study of major complications in adolescent and adult patients with thalassemia in Northeastern Thailand: the E-SAAN study phase I. Hematology 2018; 23: 55-60.

70 Derchi G, Galanello R, Bina P, et al. Prevalence and risk factors for pulmonary arterial hypertension in a large group of $\beta$-thalassemia patients using right heart catheterization: a Webthal study. Circulation 2014; 129: 338-345.

71 Parent F, Bachir D, Inamo J, et al. A hemodynamic study of pulmonary hypertension in sickle cell disease. $N$ Engl J Med 2011; 365: 44-53.

72 Fonseca GHH, Souza R, Salemi VMC, et al. Pulmonary hypertension diagnosed by right heart catheterisation in sickle cell disease. Eur Respir J 2012; 39: 112-118.

73 Mehari A, Gladwin MT, Tian X, et al. Mortality in adults with sickle cell disease and pulmonary hypertension. JAMA 2012; 307: 1254-1256.

74 Hoeper MM, Niedermeyer J, Hoffmeyer F, et al. Pulmonary hypertension after splenectomy? Ann Intern Med 1999; 130: 506-509.

75 Jaïs X, Ioos V, Jardim C, et al. Splenectomy and chronic thromboembolic pulmonary hypertension. Thorax 2005; 60: $1031-1034$

76 Freitas CSG, Baldi BG, Jardim C, et al. Pulmonary hypertension in lymphangioleiomyomatosis: prevalence, severity and the role of carbon monoxide diffusion capacity as a screening method. Orphanet J Rare Dis 2017; 12 : 74.

77 Cottin V, Harari S, Humbert M, et al. Pulmonary hypertension in lymphangioleiomyomatosis: characteristics in 20 patients. Eur Respir J 2012; 40: 630-640.

$78 \mathrm{Wu} \mathrm{X}, \mathrm{Xu} \mathrm{W}$, Wang J, et al. Clinical characteristics in lymphangioleiomyomatosis-related pulmonary hypertension: an observation on 50 patients. Front Med 2018; in press [https://doi.org/10.1007] s11684-018-0634-z].

79 Shlobin OA, Baughman RP. Sarcoidosis-associated pulmonary hypertension. Semin Respir Crit Care Med 2017; 38: 450-462.

80 Baughman RP, Engel PJ, Taylor L, et al. Survival in sarcoidosis-associated pulmonary hypertension: the importance of hemodynamic evaluation. Chest 2010; 138: 1078-1085.

81 Boucly A, Cottin V, Nunes H, et al. Management and long-term outcomes of sarcoidosis-associated pulmonary hypertension. Eur Respir J 2017; 50: 1700465.

82 Li JH, Safford RE, Aduen JF, et al. Pulmonary hypertension and thyroid disease. Chest 2007; 132 : $793-797$.

83 Badesch DB, Raskob GE, Elliott CG, et al. Pulmonary arterial hypertension: baseline characteristics from the REVEAL Registry. Chest 2010; 137: 376-387.

84 Richter MJ, Sommer N, Schermuly R, et al. The prognostic impact of thyroid function in pulmonary hypertension. J Heart Lung Transplant 2016; 35: 1427-1434. 